\title{
Formation of Precipitates on the Surface of Root Dentin After Various Final Irrigation Protocols
}

\author{
Tatjana Kanjevac ${ }^{1 *}$, Ljiljana Bjelović ${ }^{2}$, Dajana Nogo Živanović ${ }^{2}$, Bojan Kostić ${ }^{3}$ and \\ Irena Tanasković ${ }^{4}$
}

${ }^{1}$ Department of Dentistry, Serbia

${ }^{2}$ Department of Restorative Dentistry and Endodontics, Serbia

${ }^{3}$ Associate at SEM Laboratory, Serbia

${ }^{4}$ Department of Histology and embryology, Serbia

*Corresponding author: Tatjana Kanjevac, Department of Dentistry, Svetozara Markovica 69, 34000 Kragujevac, Serbia

\section{ARTICLE INFO \\ Received: 幽 January 24, 2019 \\ Published: 慧 February 07, 2019}

Citation: Tatjana $\mathrm{K}^{*}$, Ljiljana B, Dajana Nogo Ž, Bojan K, Irena T. Formation of Precipitates on the Surface of Root Dentin After Various Final Irrigation Protocols. Biomed J Sci \& Tech Res 14(2)-2019. BJSTR. MS.ID.002512.

Key words: Chlorhexidine; MTAD; Precipitate; Sodium Hypochlorite; QMiX

Abbreviations: NaOCl: Sodium Hypochlorite; EDTA: Ethylene Diamine Tetra Acetic Acid; CHX: Chlorhexidine; PCA: Parachloroaniline

\author{
ABSTRACT
}

Background: The aim of this study was to investigate the amount of precipitates formed on the surface of root dentin after irrigation with sodium hypochlorite $(\mathrm{NaOCl})$ and final chlorhexidine irrigation (CHX), ethylenediaminetetraacetic acid (EDTA) + CHX, and new combined solutions: QMiX or MTAD.

Methods: By using the method of random sampling the roots of 90 front maxillary human teeth were divided into five groups on the basis of the final irrigation protocol. The amount of precipitates is determined in the coronal, middle and apical thirds by using the by scanning electron microscopy (SEM).

Results: SEM analysis demonstrated a significantly higher amount of precipitate was formed in the CHX group compared to the MTAD group in the coronary $(p<0.05)$ that is $\mathrm{QMiX}$ group in the middle third $(\mathrm{p}<0.05)$. In the apical third, a significantly higher amount of precipitates was found in the CHX group compared to the MTAD group and the QMiX group $(\mathrm{p}<0.05)$.

Conclusion: Obtained results show that after irrigation with $\mathrm{NaOCl}$ and final irrigation with CHX more precipitate is formed than after the irrigation with $\mathrm{NaOCl}$ and final irrigation with MTAD and QMIX.

\section{Introduction}

Canalirrigation represents one of the mostimportantprocedures in the debridement of the canal space along with the mechanical instrumentation. During and after canal instrumentation, irrigants facilitate the removal of microorganisms, smear layer, as well as organic residues [1]. However, none of the irrigants meets all these requirements completely, so that during endodontic therapy, the use of multiple solutions is necessary [2]. Therefore, irrigation of the canal root with sodium hypochlorite $(\mathrm{NaOCl})$ is recommended in order to dissolve the organic component as well as final irrigation with $17 \%$ ethylenediaminetetraacetic acid (EDTA) in order to remove the inorganic component of the smear layer $[3,4]$. After smear layer removal, root canals can be finally rinsed with antiseptics, such as $\mathrm{NaOCl}$ or chlorhexidine (CHX) to attack the any remaining bacteria $[4,5]$. Recently, two new antiseptics have been introduced into the clinical practice: MTAD, which presents a mixture of isomers of doxycycline, citric acid and detergent, and QMiX, CHX solution with EDTA. They are used as final irrigants for removing the smear layer, that is as a substitute for EDTA1, but their advantage over EDTA is to exhibit less erosive effect on dentine [1-3]. Due to the existence of an antiseptic component in their composition (tetracycline or CHX), MTAD and QMiX express antimicrobial effect [5-8]. The solutions used for irrigation during endodontic therapy come into contact with each other within the root canal.

As a result of interactions, solid products known as precipitates may be formed 9. By mixing $\mathrm{NaOCl}$ and $\mathrm{CHX}$, an orange-brown precipitate is formed which can cause a change in the color of the teeth, the occlusion of dentinal tubules and the reduction in the 
dentine permeability [9-11]. Furthermore, according to some findings, the precipitate contains a toxic [12] and a carcinogenic substance [13] known as parachloroaniline (PCA). If CHX is combined with EDTA, it leads to interaction and formation of white precipitate $[14,15]$ which reduces the efficiency of EDTA solution, while mixing $\mathrm{NaOCl}$ and MTAD results in the formation of a yellow precipitate [16]. Recent studies have demonstrated that, after combining EDTA with $\mathrm{CHX}$ and $\mathrm{NaOCl}$ with MTAD, precipitate in dentine tubules is formed which disturbs the permeability of dentine in the apical third of the root [11]. The presence of the precipitate in larger amounts on the surface of dentine can significantly affect the adhesion of root dentin sealers, especially resin based sealers [17]. However, there is still a lack of data on the amount of precipitate, which is formed in these interactions on the surface of the root canal dentine. Interaction between $\mathrm{NaOCl}$ and QMiX has so far been examined in several studies that have demonstrated contradictory results.

While some studies have demonstrated that the precipitate is formed on the surface of dentine [18] and in dentine tubules 11, others have not demonstrated the presence of the precipitate either on the surface of dentine or in dentine tubules after $\mathrm{NaOCl}$ and QMiX canal flushing [19]. Its amount in the interaction between $\mathrm{NaOCl}$ and QMiX has not yet been determined.Therefore, the aim of this study was to determine the amount of the precipitate formed on the root dentine surface after $\mathrm{NaOCl}$ irrigation and final irrigation with CHX, EDTA + CHX, QMiX or MTAD. The investigated null hypothesis was that there was no difference between various final irrigants in the amount of precipitate formed on the surface of the root dentine.

\section{Material and Methods \\ Preparation of Samples}

The protocol of this study was approved by the Ethical Committee of Faculty of Medicine (No: 01-3-88 / 2015). Ninety extracted frontal maxillary human teeth extracted for prosthodontics reasons were collected. Criteria for the inclusion in the study were: an intact tooth, previously not treated endodontically and without coronary restoration. Radiographic evaluations were employed to verify the presence of one central root canal, normal pulp chamber, and fully formed apex. The crowns of the tooth were cut off so as to provide a standardized root length of $14 \mathrm{~mm}$. After that, by using the method of random sampling, the roots were divided into five groups ( $\mathrm{n}=$ 18) depending on the type of the irrigant used for the final iriigation: CHX (2\% CHX solution, Consepsis, Dentsply Tulsa Dental, Tulsa, OK, USA), EDTA + CHX (17\% EDTA, ENDO-SOLution, Cerkamed, PPH Cerkamed, Stalowa Wola, Poland / 2\% CHX Solution, Consepsis, Dentsply Tulsa Dental, Tulsa, OK, USA), QMiX (Dentsply Tulsa Dental, Tulsa , OK, USA), MTAD (Dentsply Tulsa Dental, Tulsa, OK, USA), and a control group (distilled water). An ISO size \#15 K-type file (Dentsply Maillefer, Ballaigues, Switzerland) was inserted into the canal until the tip of the file was observed at the apical foramen and working length was determined subtracting $1 \mathrm{~mm}$ from the recorder distance. All apices of the root are sealed with wax to simulate clinical conditions.

Canals were prepared by machine tools Protaper Universal (Dentsply, Maillefer, Ballaigues, Switzerland) up to F4 size (40 /
0.06). After each instrument, canals were irrigated with $1 \mathrm{ml}$ of $5.25 \% \mathrm{NaOCl}$, except for the roots in the MTAD group, where $1.3 \%$ $\mathrm{NaOCl}$ was used (manufacturer's recommendation). Before the final irrigation, a smear layer was removed with $5 \mathrm{ml}$ of 17\% EDTA for 5 minutes from the surface of the dentinal wall of the canal, and then with distilled water, so that only the precipitate could remain on the dentine surface.The final irrigation protocol was implemented as follows: CHX group: $5 \mathrm{ml} 5.25 \% \mathrm{NaOCl}$ (2 minutes) + $10 \mathrm{ml}$ distilled water ( 2 minutes $)+5 \mathrm{ml} \mathrm{CHX} \mathrm{(2} \mathrm{minutes);} \mathrm{CHX} \mathrm{+}$ EDTA group: $5 \mathrm{ml} 5.25 \% \mathrm{NaOCl}$ (2 minutes) $+10 \mathrm{ml}$ distilled water ( 2 minutes $)+5 \mathrm{ml}$ 17\% EDTA ( 2 minutes $)+10 \mathrm{ml}$ distilled water (2 minutes) + $5 \mathrm{ml} 2 \%$ CHX (2 minutes); QMIX group: $5 \mathrm{ml} \mathrm{5.25 \%}$ $\mathrm{NaOCl}$ (2 minutes) + $10 \mathrm{ml}$ distilled water (2 minutes) + $5 \mathrm{ml}$ QMIX (2 minutes); MTAD group: $5 \mathrm{ml} \mathrm{1.3 \%} \mathrm{NaOCl}$ ( 2 minutes) $+10 \mathrm{ml}$ distilled water ( 2 minutes) +5 ml MTAD ( 2 minutes); Control group: $5 \mathrm{ml} 5.25 \% \mathrm{NaOCl}$ ( 2 minutes) $+10 \mathrm{ml}$ distilled water ( 2 minutes) $+5 \mathrm{ml}$ distilled water ( 2 minutes). All irrigating solutions were introduced with a 27-G syringe needle (Endo Easy Tip, Ultradent products Inc.) inserted to $1 \mathrm{~mm}$ of the working length. After the final irrigation was completed, canals were dried by paper points.

\section{Scanning Electron Microscopic (SEM) Analysis}

Eighteen roots from each group were prepared for SEM analysis. On the buccal and oral surfaces of the root, longitudinal grooves are made by using a diamond disc and the by using a chisel canals are divided into two halves. One randomly chosen half of each specimen was coded and subjected to increasing concentrations of ethanol (25\%,50\%, 75\% and 100\%), mounted on aluminum holder, sputter coated with gold and analyzed by SEM (SEM, JEOL-JSM-6610LV, Tokyo, Japan) in order to determine the presence of the precipitate on the root dentine surface. The coronal (12 $\mathrm{mm}$ from apex), the middle (7 $\mathrm{mm}$ from apex) and the apical ( $2 \mathrm{~mm}$ from apex) third were analyzed at an increase of $500 \mathrm{x}$, $2,000 \mathrm{x}$ and $4,500 \mathrm{x}$. The $2.000 \mathrm{x}$ magnification micrographics were preserved in TIFF format and the representative areas of each root third are analyzed using Adobe Photoshop CS5, Adobe Systems. All images were standardized at the size of $47 \mu \mathrm{m} \times 63 \mu \mathrm{m}$ and the number of pixels of the entire image was determined. After that, the surface of the image with the resulting precipitate was indicated by a magnetic pointer and the number of pixels was determined. By dividing these two values, the percentage of the precipitate for each image was calculated.

\section{Statistical Analysis}

Statistical data processing was done in the statistic program SPSS 20.0 (IBM Corp., Armonk, NY, USA). Since percentages of precipitates did not follow normal distribution (KolmogorovSmirnov test $\mathrm{p}<0.05$ ), the differences between and within groups were determined by using the Kruskal-Wallis test and the post hoc Dunn test. The significance levels were set at $5 \%$.

\section{Results}

SEM analysis demonstrated that after various irrigation protocols on the surface of dentin, precipitate was formed in all investigated groups. Precipitate was not observed on the samples of the control group (Figures 1a-1c). In the CHX group, the precipitate covers a larger area of dentine in all root thirds (Figures 2a-2c). In 
the EDTA + CHX group, precipitation is observed in all root thirds to a lesser extent than in the CHX group (Figures 3a-3c), while the lowest amount of the precipitate was formed using MTAD (Figures 4a-4c) and QMiX group (Figures 5a-5c). The highest amount of the precipitate was recorded in the CHX group. Data analysis showed that the amount of the precipitate in this group was significantly higher in relation to the MTAD group $(\mathrm{p}<0.05)$ in the coronal third and compared to the QMiX group in the middle third $(p<0.05)$.
In the apical third, the amount of the precipitate formed in the CHX group was significantly higher than that in the QMiX and the MTAD group ( $\mathrm{p}<0.05)$. A significant difference in the amount of the precipitate was recorded in the apical third and between EDTA + CHX and MTAD group ( $\mathrm{p}<0.05)$. Observed by root thirds, the highest amount of the precipitate was found in the coronal and the lowest in the apical third in all groups, but this difference did not reach any statistical significance ( $p>0.05)$ (Table 1$)$.

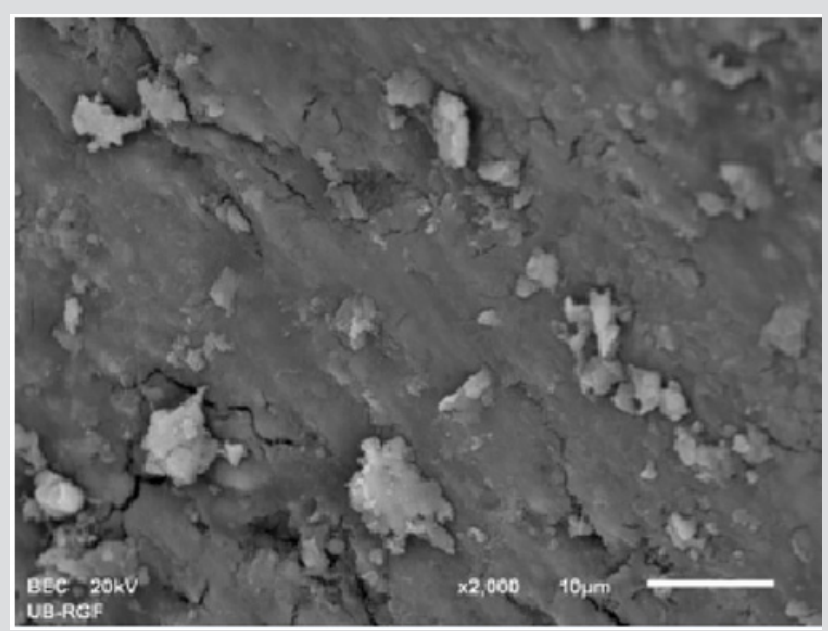

Figure 1a: SEM micrographs $(2000 \mathrm{x})$ of the precipitate on the surface of dentin root canal after CHX irrigation in appical third.

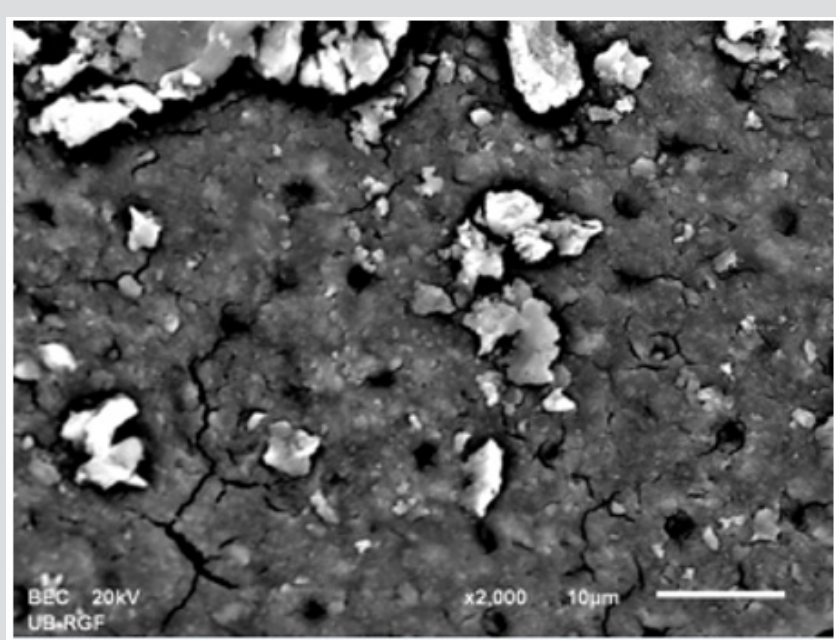

Figure 1b: SEM micrographs $(2000 \mathrm{x})$ of the precipitate on the surface of dentin root canal after CHX irrigation in middle third.

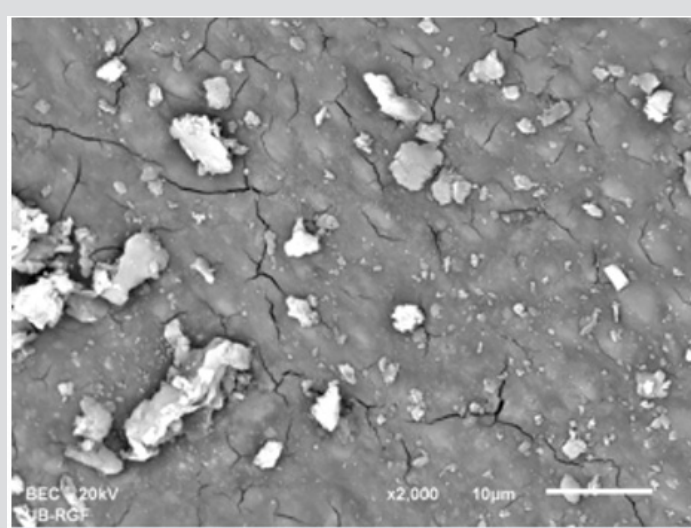

Figure 1c: SEM micrographs $(2000 \mathrm{x})$ of the precipitate on the surface of dentin root canal after $\mathrm{CHX}$ irrigation in coronary third. 


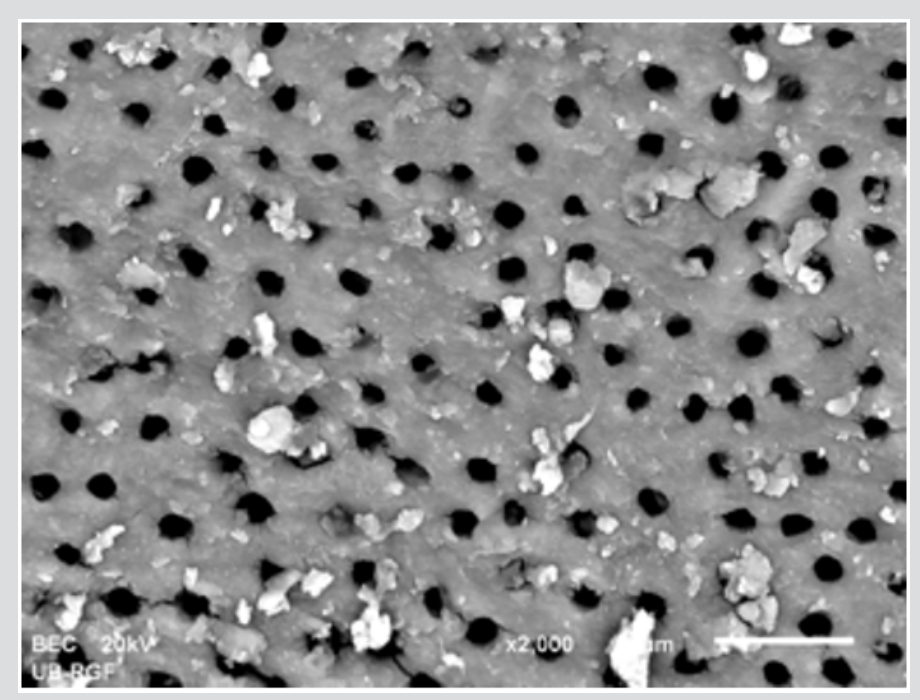

Figure 2a: SEM micrographs $(2000 \mathrm{x})$ of the precipitate on the surface of dentin root canal after EDTA+ CHX irrigation in appical third.

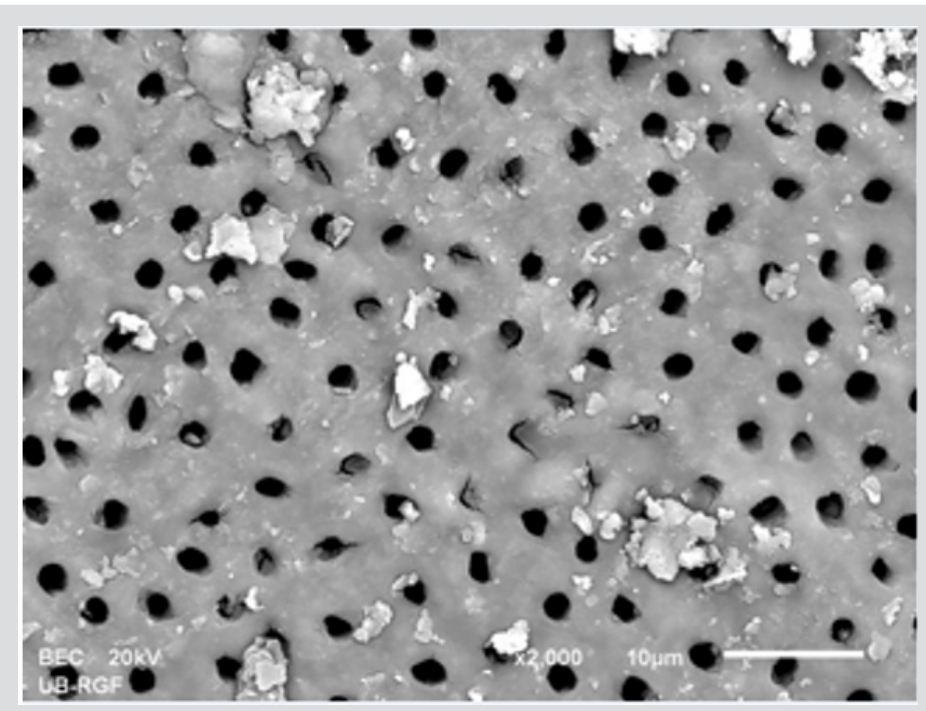

Figure 2b: SEM micrographs $(2000 \mathrm{x})$ of the precipitate on the surface of dentin root canal after EDTA+ CHX irrigation in middle third.

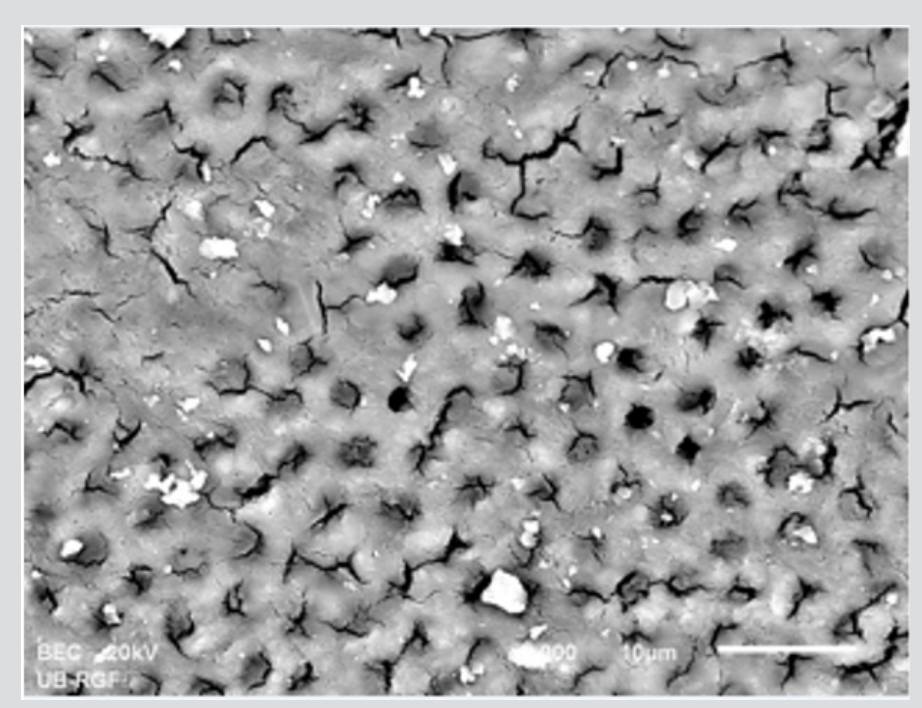

Figure 2c: SEM micrographs $(2000 \mathrm{x})$ of the precipitate on the surface of dentin root canal after EDTA+ CHX irrigation in coronary third. 


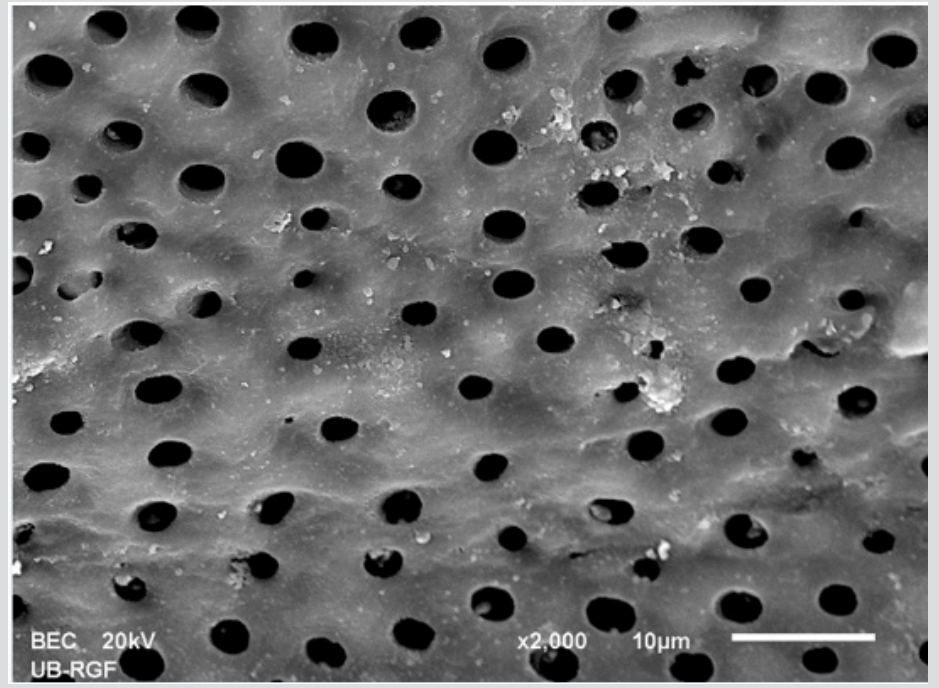

Figure 3a: SEM micrographs $(2000 \mathrm{x})$ of the precipitate on the surface of dentin root canal after MTAD irrigation in appical third.

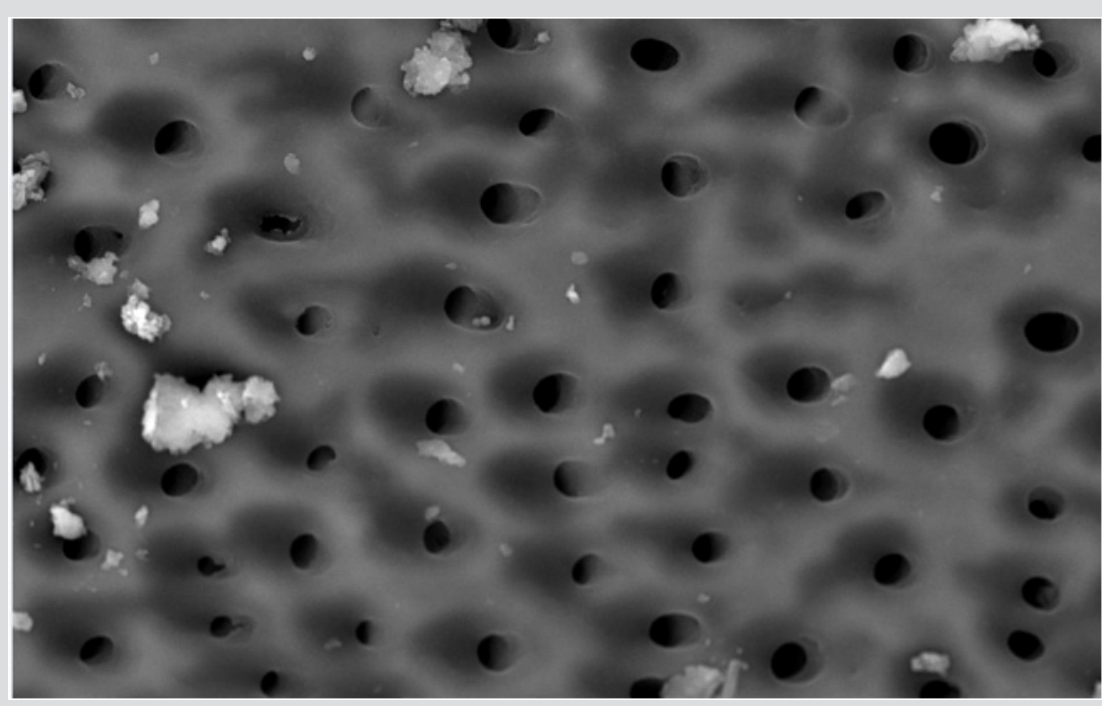

Figure 3b: SEM micrographs $(2000 \mathrm{x})$ of the precipitate on the surface of dentin root canal after MTAD irrigation in middle third.

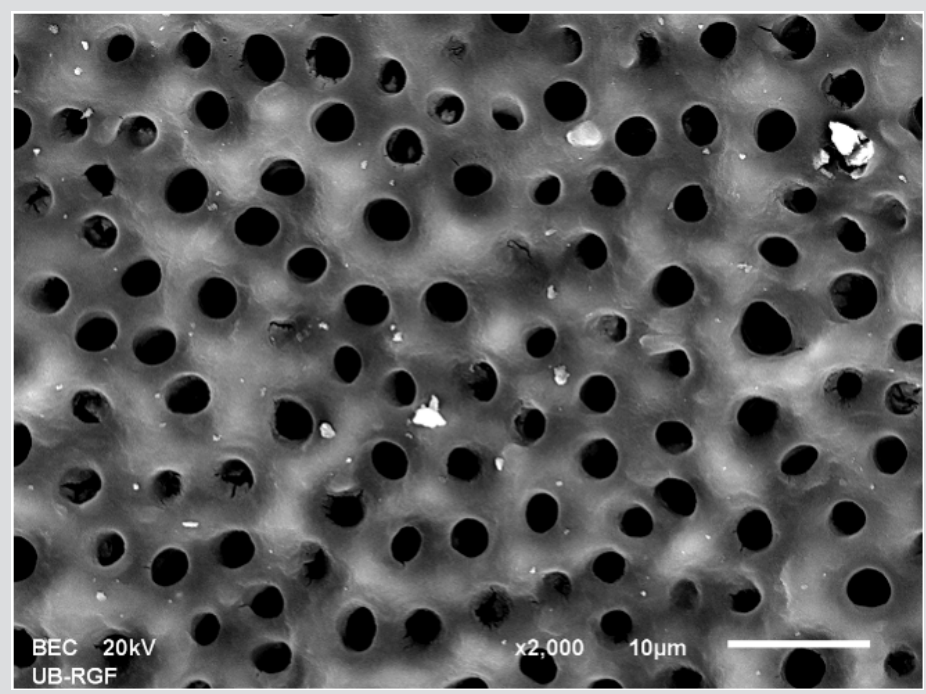

Figure 3c: SEM micrographs $(2000 \mathrm{x})$ of the precipitate on the surface of dentin root canal after MTAD irrigation in coronary third. 


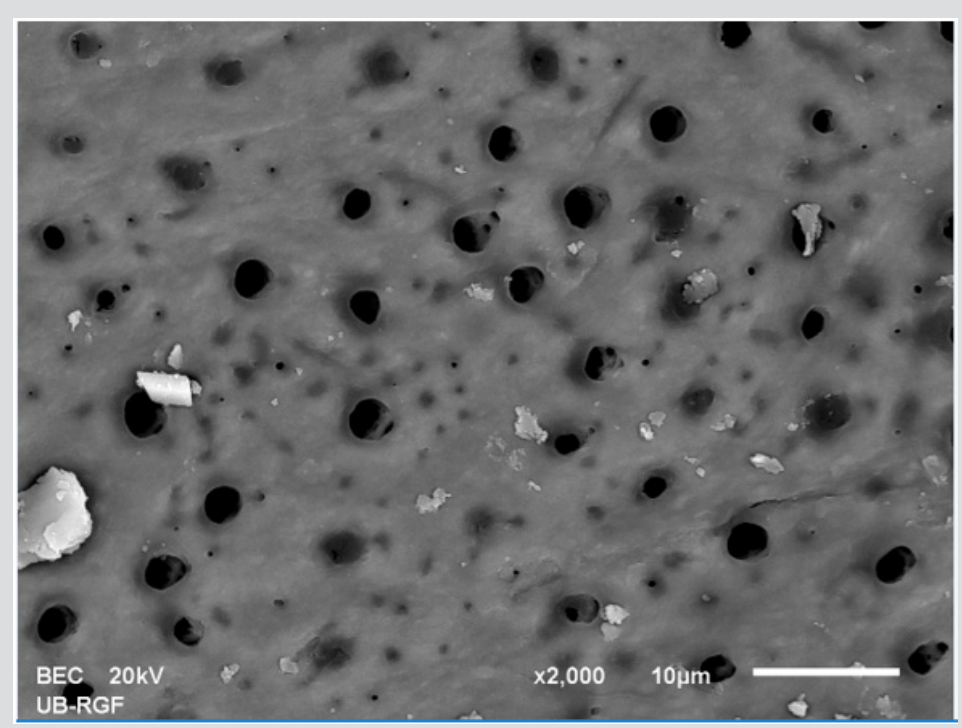

Figure 4a: SEM micrographs (2000 x) of the precipitate on the surface of dentin root canal after QMiX irrigation in appical third.

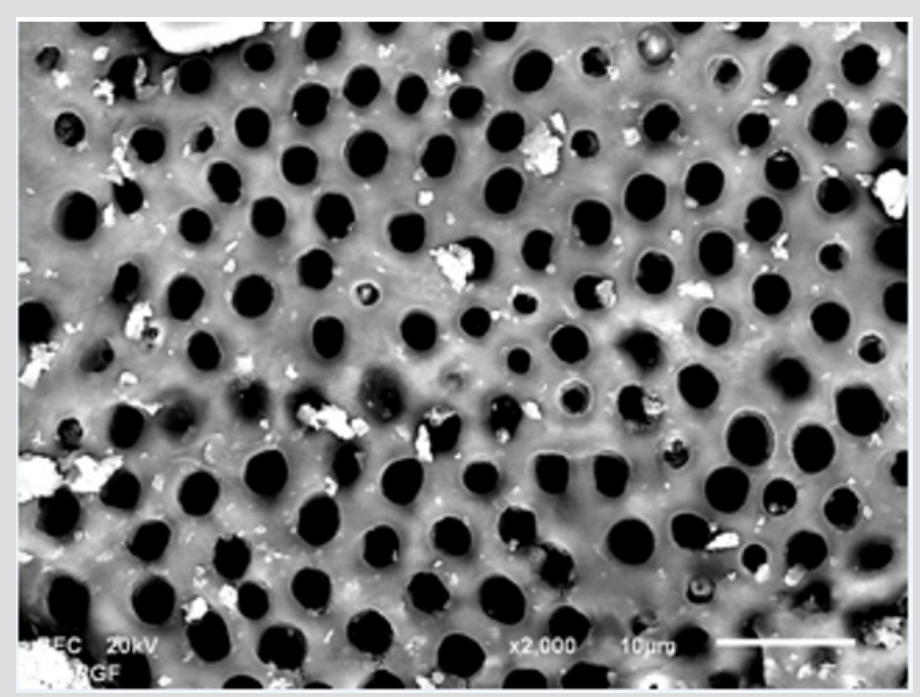

Figure 4b: SEM micrographs $(2000 \mathrm{x})$ of the precipitate on the surface of dentin root canal after QMiX irrigation in middle third.third.

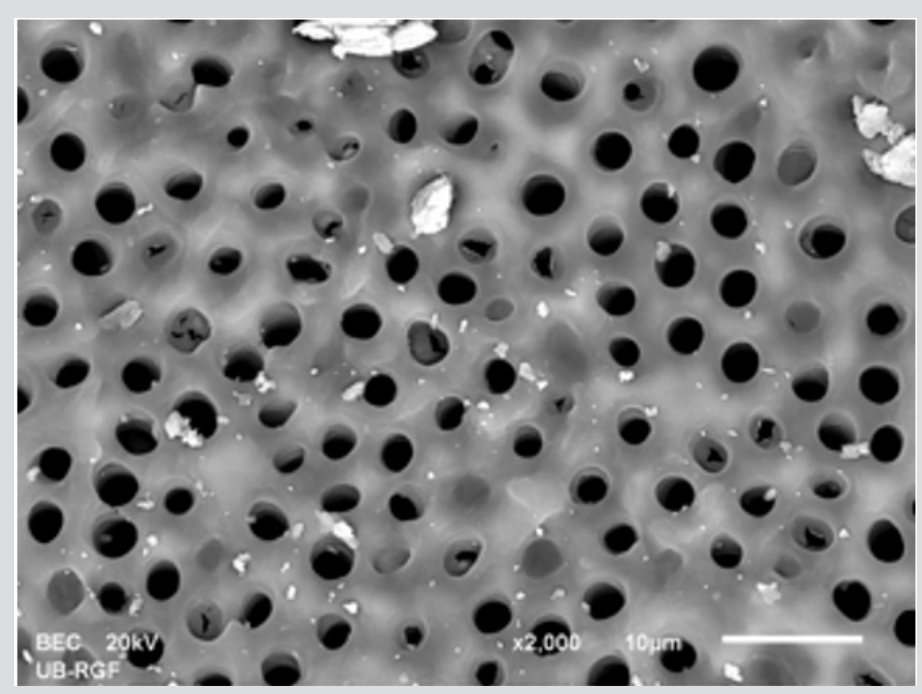

Figure 4c: SEM micrographs $(2000 \mathrm{x})$ of the precipitate on the surface of dentin root canal after QMiX irrigation in coronary third. 


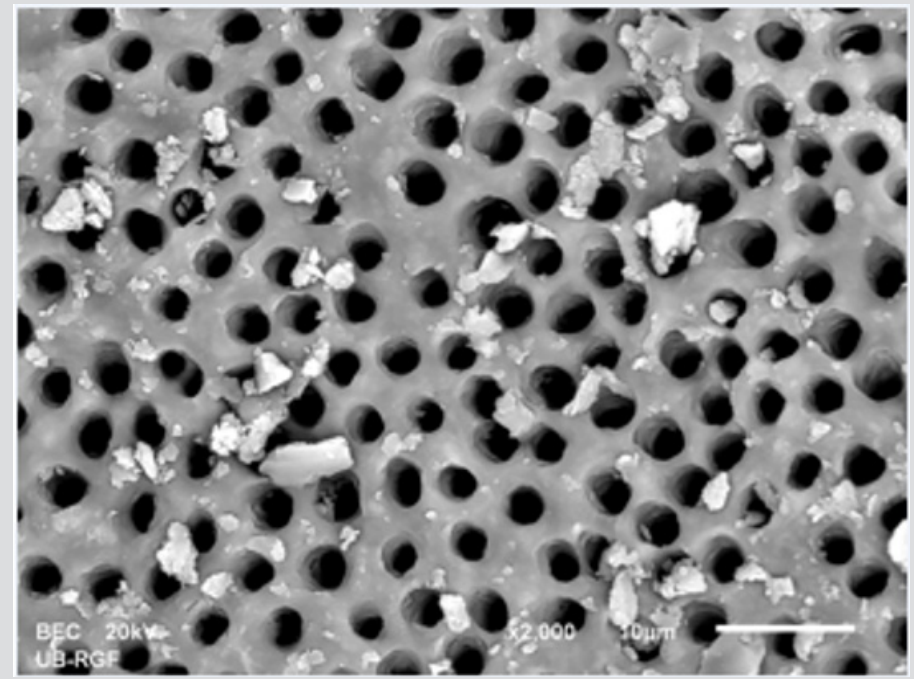

Figure 5a: SEM micrographs $(2000 \mathrm{x})$ of the precipitate on the surface of dentin root canal after distilled water irrigation in apical third.

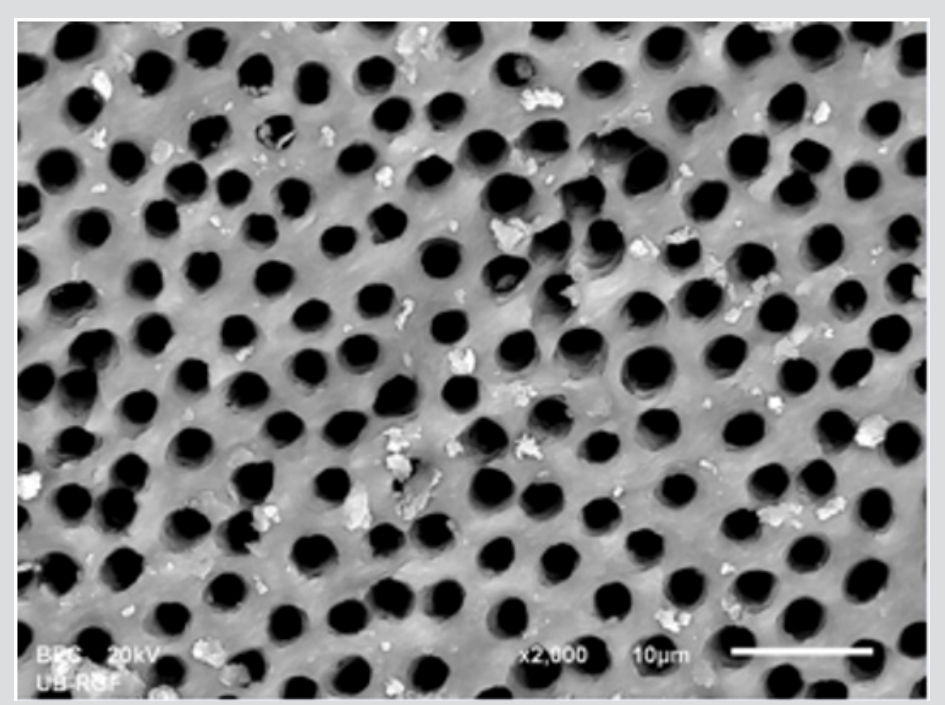

Figure 5b: SEM micrographs $(2000 \mathrm{x})$ of the precipitate on the surface of dentin root canal after distilled water irrigation in middle third.

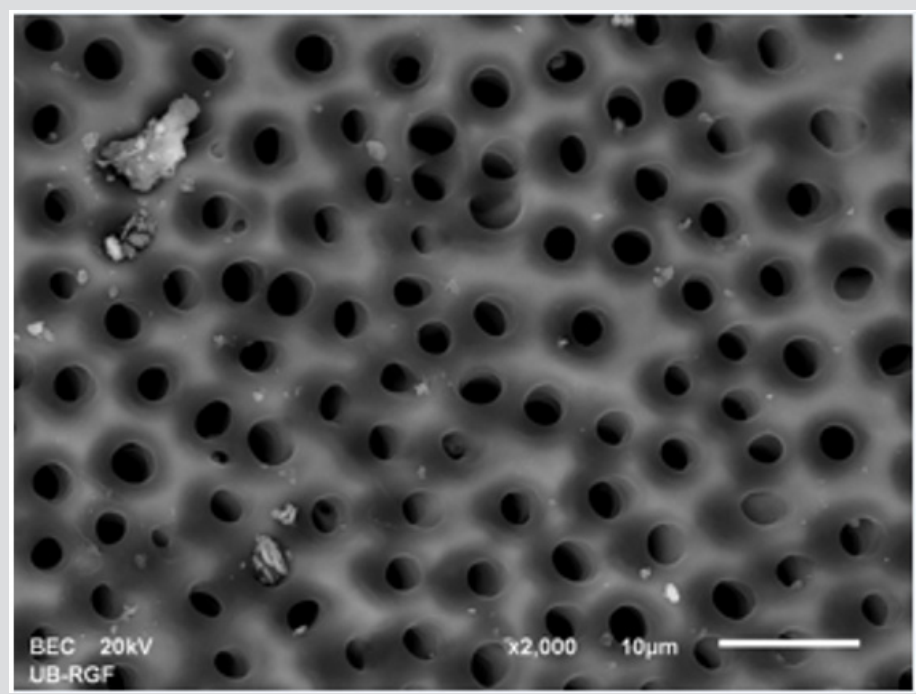

Figure 5c: SEM micrographs $(2000 \mathrm{x})$ of the precipitate on the surface of dentin root canal after distilled water irrigation in coronary third. 
Table 1: The amount of the precipitate (\%) formed on the surface of the root canal dentine after various irrigation protocols.

\begin{tabular}{|c|c|c|c|c|}
\hline Third & CHX group Mean (SD) & $\begin{array}{c}\text { EDTA + CHX groupa Mean } \\
\text { (SD) }\end{array}$ & QMiX group Mean (SD) & MTAD group Mean (SD) \\
\hline Coronal & $13,13 \pm 13,47^{\mathrm{Aa}}$ & $7,30 \pm 4,92^{\mathrm{ABa}}$ & $4,34 \pm 3,04^{\mathrm{ABa}}$ & $4,69 \pm 5,02^{\mathrm{Ba}}$ \\
\hline Middle & $11,81 \pm 14,23^{\mathrm{Aa}}$ & $6,79 \pm 6,54^{\mathrm{ABa}}$ & $3,85 \pm 4,12^{\mathrm{Ba}}$ & $4,30 \pm 4,67^{\mathrm{ABa}}$ \\
\hline Apical & $10,07 \pm 5,96^{\mathrm{Aa}}$ & $6,70 \pm 4,49^{\mathrm{ABa}}$ & $3,57 \pm 4,47 \mathrm{~B}^{\mathrm{Ca}}$ & $3,66 \pm 4,92^{\mathrm{Ca}}$ \\
\hline
\end{tabular}

\section{Discussion}

SEM analysis demonstrated that the precipitate was created after $\mathrm{NaOCl}$ irrigation and final irrigation with $\mathrm{CHX}$, EDTA + CHX, MTAD or QMiX. Taking into account that the amount of the precipitate produced in CHX group was significantly higher compared to MTAD (coronary and apical third) and QMiX group (middle and apical third) the null hypothesis was discarded.The SEM analysis demonstrated that the precipitate was not formed on the surface of dentine in the samples treated with $5.25 \% \mathrm{NaOCl}$ and distilled water (control group). On the other hand, in the root canals, which were flushed with various final irrigants, the precipitate was found on the surface of dentine. Irrigation of the root canal with $5.25 \% \mathrm{NaOCl}$ and 2\% CHX was followed by the formation of the precipitate, which was not prevented even by the use of distilled water as an intermediate irrigant, which is in line with the results of other studies [20,21,22]. In the interaction between $\mathrm{NaOCl}$ and CHX, the formation of a neutral and insoluble brown precipitate was due to the acid-base reaction [9]. In addition to $\mathrm{NaOCl}$, CHX can react with EDTA as well. This reaction results in the formation of an insoluble pink 22 or whitish precipitate $[14,15]$. This precipitate is probably salt formed by the neutralization of CHX by EDTA. Our results show that final flushing with solutions of $17 \%$ EDTA $+2 \%$ CHX results in the formation of the precipitate on the surface of dentine.

Also, in our study, the application of distilled water between the application of 17\% EDTA and 2\% CHX did not prevent precipitation. Prado et al. [15] showed that the flushing of the canal with distilled water after $2 \%$ CHX and before the use of 17\% EDTA prevented the formation of a chemical smear layer that is precipitate. However, if the canals are flushed with $5.25 \% \mathrm{NaOCl}$, then with $17 \%$ EDTA and finally with $2 \%$ CHX the precipitate is formed on the surface of dentine, despite the fact that between each irrigant the root canal is flushed with distilled water [23], which is consistent with the results of our research. It is assumed that the newly formed precipitate is the result of the presence of $\mathrm{NaOCl}$ and its interaction with CHX rather than the result of the interaction of CHX and EDTA [23]. It is possible that CHX from QMiX reacts with $\mathrm{NaOCl}$. In the QMiX solution, the interaction between CHX and EDTA is prevented by the chemical design of the solution [7]. According to some findings, combining $\mathrm{NaOCl}$ and QMiX may cause a color change of the solution, but without the formation of the precipitate [24], so it is recommended by the manufacturer to flush the canal of the root with saline solution between these two irrigants [24]. Kolosowski at al. also speak on behalf of this [19] with their studies which did not find the precipitate on the surface of the dentine of dentine blocks that were immersed in $2.5 \% \mathrm{NaOCl}$, and after that in saline and QMiX, using secondary mass spectroscopic analysis (TOF-SIMS).
On the other hand, the spectroscopic analysis of the surface of the dentin of root canal Arslan et al. [18] showed that the flushing of the canal with $2.5 \% \mathrm{NaOCl}$ and QMiX, without intermediate flushing, resulted in the formation of orange-brown precipitate on the surface of dentine. Similar results occurred in our SEM study where the application of QMiX after 5.25\% $\mathrm{NaOCl}$ was followed by the formation of the precipitate on the surface of the root canal although the canal was flushed with distilled water between the two irrigants. Differences in the results between our and the above studies can be attributed to the differences in the concentration of the applied $\mathrm{NaOCl}$. It has also been shown that the type of intermediate irrigant used to remove $\mathrm{NaOCl}$ prior to final $\mathrm{CHX}$ irrigation can have an effect on the formation of the precipitate [15, 20,25]. Different results between studies can be attributed to differences in methods used to visualize the precipitate, as well as to the characteristics of samples and irrigation protocols. Namely, in the study conducted by Kolosowski at al. 19 dentine blocks were opened at both ends, which allowed the same exposure and an adequate replacement of irrigants in all samples, probably preventing interaction between them, as opposed to the study conducted by Arslan et al. [18] and our research as well in which the sample were root canals flushed by using a syringe and a needle, where it is not possible to deliver the same amount of irrigants into all parts of the canal. In the study by Tay et al. 16, it was observed that by mixing $\mathrm{NaOCl}$ and MTAD, a yellow precipitate was formed which, after remaining in the bottle for a longer time, changed the color to orange-yellow. Also, these authors noted the formation of yellow precipitate along the walls of the root canal after using $1.53 \%-6.15 \% \mathrm{NaOCl}$ with final MTAD flushing in clinical conditions [16]. This interaction is a redox reaction in which oxidation of doxycycline in the presence of $\mathrm{NaOCl}$ occurs [16].

The findings from our study are also in accordance with the results of the mentioned research. Specifically, the precipitate was observed on the surface of the root dentin after the irrigation of the root canal with $1.3 \% \mathrm{NaOCl}$ and final flushing with MTAD. It is interesting to note that the application of distilled water after $1.3 \% \mathrm{NaOCl}$ did not prevent formation of the precipitation [16]. The amount of precipitate formed after flushing with $5.25 \% \mathrm{NaOCl}$ and final flushing with $2 \%$ CHX was two to three times higher than the amount of the precipitate formed in other groups. A statistically significant difference in the amount of precipitation between the CHX group and other groups was recorded only in the coronal and apical third relative to the MTAD group and the middle and apical third in relation to the QMiX group, which is probably a consequence of high standard deviations in each of the examined groups. The precipitate formed in the interaction of $\mathrm{NaOCl}$ and $\mathrm{CHX}$ reduces the permeability of dentine, which was confirmed in our previous research [11] and the works of other authors [26, 27]. The amount 
of the precipitate in the EDTA + CHX group and the QMiX group did not differ significantly, but the precipitate in the EDTA + CHX group was almost twice as high. This can be explained by a lower amount of CHX in the QMiX solution available for interaction with $\mathrm{NaOCl}$ compared to $2 \%$ CHX, which was used in the EDTA + CHX group. Namely, the interaction between $\mathrm{NaOCl}$ and $\mathrm{CHX}$ and the formation of the precipitate depends on the concentration of $\mathrm{NaOCl}$ on one hand [9] and the concentration of CHX on the other [28].

Flushing of the canal with a lower concentration of $\mathrm{NaOCl}$ (1.3\%) before the final flushing with MTAD resulted in the formation of a lower amount of the precipitate in this group. Although there are data on the effect of the precipitate formed in the interaction between $\mathrm{NaOCl}$ and $\mathrm{CHX}$ on the surface of dentine, the influence of the precipitate formed in the interactions of $\mathrm{NaOCl}$ and EDTA + CHX, $\mathrm{NaOCl}$ and MTAD, as well as NaOCl and QMiX are insufficiently tested. Observed by root thirds, the highest amount of the precipitation in our study was observed in the coronal and the lowest in the apical third of the canal in all examined groups. By using the stereomicroscope for examining the interaction between $2.5 \%$ $\mathrm{NaOCl}$ and 2\% CHX, Krishnamurthy \& Sudhakaran [20] measured the greatest thickness of the precipitate in the coronal and the smallest one in apical third, with a significant difference between the apical and the other two thirds. The observed differences in the amount of the precipitate per root thirds in our study can be attributed to canal anatomy and limitations of irrigation by the application of a syringe and a needle, which prevent the delivery of the same amounts of irrigants to all parts of the canal.

\section{Conclusion}

The results of our study show that higher amounts of the precipitate are produced after the final CHX irrigation, than in the case of MTAD and QMiX combination. Determining the chemical composition of the formed precipitate and its effect on the disinfection of the canal system and the adhesion of sealers to root dentin, would be interesting both from scientific and clinical aspects.

\section{Acknowledgement}

The study was supported by the Junior Project (No: 2016/06) of the Faculty of Medical Sciences at the University of Kragujevac and the Project of the Ministry of Education, Science and Technological Development of the Republic Serbia (Br: 175071).

\section{References}

1. Basrani B, Haapasalo M (2012) Update on endodontic irrigating solutions. Endod Topics 27(1): 74-102.

2. Nogo Zivanovic D, Bjelovic LJ, Ivanovic V, Kanjevac T, Tanacković I (2018) Consideration of therapeutic possibilities of irrigants in endodontic therapy. Ser J Exp Clin Res 19(2): 103-112.

3. Zehnder M (2006) Root canal irrigants. J Endod 32(5): 389-398.

4. Rôças IN, Siqueira JF (2011) Comparison of the in vivo antimicrobial effectiveness of sodium hypochlorite and chlorhexidine used as root canal irrigants: a molecular microbiology study. J Endod 37(2): 143-150.

5. Souza MA, Montagner A, Lana DL, Vidal CM, Farina AP, et al. (2017) Comparative evaluation of the retaining of QMix and chlorhexidine formulations on human dentin: a chemical analysis. Clin Oral Investig 21(3): 873-878.
6. Rasimick BJ, Wan J, Musikant BL, Deutsch AS (2010) Stability of doxycycline and chlorhexidine absorbed on root canal dentin. J Endod 36(3): 489-492.

7. Stojicic S, Shen Y, Qian W, Johnson B, Haapasalo M (2012) Antibacterial and smear layer removal ability of a novel irrigant, QMiX. Int Endod J 45(4): 363-371.

8. Jardine AP, Rosa RA, Santini MF, Wagner M, Só MV, et al. (2016) The effect of final irrigation on the penetrability of an epoxy resin-based sealer into dentinal tubules: a confocal microscopy study. Clin Oral Investig 20(1): 117- 123.

9. Basrani BR, Manek S, Sodhi RN, Fillery E, Manzur A (2007) Interaction between sodium hypochlorite and chlorhexidine gluconate. J Endod 33(8): 966-969.

10. Bui TB, Baumgartner JC, Mitchell JC (2008) Evaluation of the interaction between sodium hypochlorite and chlorhexidine gluconate and its effect on root dentin. J Endodod 34(2): 181-185.

11. Bjelović Lj, Krunić J, Stojanović N, Erić J, Kanjevac T (2018) Evaluation of permeability of root dentin after different irrigation protocols. Serb Arch Med.

12. Boehncke A, Kielhorn J, Koennecker G, Pohlenz Michel C, Mangelsdorf I (2003) Concise International Chemical Assessment Document, 4-Chloroaniline. World Health Organization, Switzerland, p. 48.

13. Chhabra RS, Huff JE, Haseman JK, Elwell MR, Peters AC (1991) Carcinogenicity of p-chloroaniline in rats and mice. Food Chem Toxicol 29(2): 119-124.

14. Rasimick BJ, Nekich M, Hladek MM, Musikant BL, Deutsch AS (2008) Interaction between chlorhexidine digluconate and EDTA. J Endod 34(12): 1521-1523.

15. Prado M, Santos Júnior HM, Rezende CM, Pinto AC, Faria RB, et al. (2013) Interactions between irrigants commonly used in endodontic practice: a chemical analysis. J Endod 39(4): 505-510.

16. Tay FR, Mazzoni A, Pashley DH, Weller RN, King NM, et al. (2006) Ultrastructure of smear layer-covered intraradicular dentin after irrigation with BioPure MTAD. J Endod 32(3): 218-221.

17. Vivacqua Gomes N, Ferraz CC, Gomes BP, Zaia AA, Teixeira FB, et al. (2002) Influence of irrigants on the coronal microleakage of laterally condensed gutta-percha root fillings. Int Endod J 35(9): 791-795.

18. Arslan H, Uygun AD, Keskin A, Karatas E, Seçkin F, et al. (2015) Evaluation of orange-brown precipitate formed in root canals after irrigation with chlorhexidine and QMix and spectroscopic analysis of precipitates produced by a mixture of chlorhexidine/ $\mathrm{NaOCl}$ and $\mathrm{QMix} / \mathrm{NaOCl}$. Int Endod J 48(12): 1199-1203.

19. Kolosowski KP, Sodhi RN, Kishen A, Basrani BR (2014) Qualitative analysis of precipitate formation on the surface and in the tubules of dentin irrigated with sodium hypochlorite and a final rinse of chlorhexidine or QMiX. J Endod 40(12): 2036-2040.

20. Krishnamurthy S, Sudhakaran S (2010) Evaluation and prevention of the precipitate formed on interaction between sodium hypochlorite and chlorhexidine. J Endod 36(7): 1154-1157.

21. Magro MG, Kuga MC, Aranda Garcia AJ, Victorino KR, Chávez Andrade GM, et al. (2015) Effectiveness of several solutions to prevent the formation of precipitate due to the interaction between sodium hypochlorite and chlorhexidine and its effect on bond strength of an epoxy-based sealer. Int Endod J 48(5): 478-483.

22. González López S, Camejo Aguilar D, Sanchez P, Bolaños Carmona V (2006) Effect of CHX on the decalcifying effect of 10\% citric acid, $20 \%$ citric acid, or 17\% EDTA. J Endod 32(8): 781-784.

23. Do Prado M, Simão RA, Gomes BP (2013) Evaluation of different irrigation protocols concerning the formation of chemical smear layer. Microsc Res Tech 76(2): 196-200.

24. (2012) Dentsply Tulsa Dental Specialities. $\mathrm{QMiX}^{\circledR} 2$ in 1 Irrigating Solution, Directions for Use. 
25. Mortenson D, Sadilek M, Flake NM Paranjpe A, Heling I, et al. (2012) The effect of using an alternative irrigant between sodium hypochlorite and chlorhexidine to prevent the formation of para-chloroaniline within the root canal system. Int Endod J 45(9): 878-882.

26. Paqué F, Luder HU, Sener B, Zehnder M (2006) Tubular sclerosis rather than the smear layer impedes dye penetration into the dentine of endodontically instrumented root canals. Int Endod J 39(1): 18-25.

\section{ISSN: 2574-1241}

DOI: 10.26717.BJSTR.2019.14.002512

Tatjana Kanjevac.Biomed J Sci \& Tech Res

(C) This work is licensed under Creative

Submission Link: https://biomedres.us/submit-manuscript.php
27. Akisue E, Tomita VS, Gavini G, Poli de Figueiredo JA (2010) Effect of the combination of sodium hypochlorite and chlorhexidine on dentinal permeability and scanning electron microscopy precipitate observation. J Endod 36(5): 847-850.

28. Gasic J, Popovic J, Zivković S, Petrovic A, Barac R, et al. (2012) Ultrastructural analysis of the root canal walls after simultaneous irrigation of different sodium hypochlorite concentration and $0.2 \%$ chlorhexidine gluconate. Microsc Res Tech 75(8): 1099-1103.

$\begin{array}{ll}\text { BIOMEDICAL } & \text { Assets of Publishing with us } \\ \text { RESEARCHES } & \text { - Global archiving of articles } \\ & \text { - Immediate, unrestricted online access } \\ & \text { - Rigorous Peer Review Process } \\ \end{array}$

